ISSN: 1887-2417 ISSN-e: 2386-4362 DOI: 10.17979/ams.2017.23 24.0.3385

\title{
A educação ambiental na sustentabili- dade da vida em uma experiência de alfabetização de catadores
} The environmental education in the sustainability of life in a literacy experience of waste pickers

Dinorá de Castro Gomes e Vera Margarida Lessa Catalão. Universidade de Brasilia (Brasil)

\begin{abstract}
Resumo
Inserido no universo da educação ambiental este artigo apresenta uma discussão, decorrente de uma pesquisa de doutorado, sobre a contribuição da Educação Ambiental para alfabetização e formação humana junto a uma turma de trabalhadores em uma cooperativa de catadores de resíduos sólidos na cidade de Goiânia, Goiás, Brasil. A experiência buscou interfaces entre a Educação Ambiental (EA) e a Educação Popular (EP), tendo como referência a transversalidade, conforme René Barbier, e a educação libertadora, na concepção de Paulo Freire. A observação participante, a roda de conversa e as entrevistas semiestruturadas foram procedimentos utilizados para construção dos dados. A experiência ampliou o olhar em relação ao papel socioambiental dos catadores e à relevância da educação ambiental como geradora da percepção de pertencimento do catador à sociedade humana. Enfatizou o reconhecimento do catador como um profissional, de acordo com a lei 12.305/2010, que institui a Política Nacional de Resíduos Sólidos, e favoreceu o enfrentamento do sentimento de marginalidade. Ressalta-se a importância da contribuição da EA para a efetivação de uma educação transformadora, fortalecendo os princípios da EP. Elos submersos emergiram ao articular o compromisso com as mudanças sociais e com a sustentabilidade da teia da vida em escala local e planetária.
\end{abstract}

\section{Astract}

Inserted in the universe of environmental education this article presents a discussion, descending from a doctorate research, about the contribution of Environmental Education for the alphabetization and human formation among a classroom of workers in an union of solid waste collection in the city of Goiânia, Goiás, Brazil. The experience sought interfaces between the Environmental Education (EA) and Popular Education $(P E)$, having as a reference the transversality, according to René Barbier, and the freeing education, as conceived by Paulo Freire. The participating observation, the circle of conversation and the interviews semi-structured were procedures utilized for the construction of data. The experience amplified the view in relation to the socioenvironmental role of the solid waste collectors and the relevancy of environmental education as generator of the perception of belonging of the collector into human society. Emphasized the recognition of the solid waste collector as a professional, according with the law 12.305/2010 that institutes a National Policy of Solid Waste, and favored the confrontation of the feeling of marginality. Stands out the importance 
of the contribution of the EA for the effectiveness of a transformative education, strengthening the principles of the PE. Submerged ties emerged when the compromise with the social changes and sustainability of the web of life in local and planetary scale emerged.

\section{Palavras chave}

Educação Ambiental; Alfabetização de Catadores; Formação Humana; Resíduos Sólidos.

\section{Key-words}

Environmental Education; Alphabetization of Collectors; Human Formation; Solid Waste.

CA TA DOR

Cata cata catador

Cata as sobras pelo chão

Cata os resíduos da vida

Cata a semente do pão

Cata cata catador

Cata o Sol e cata a Lua

Cata o sonho e cata a lida

Cata a sina que é tua

Cata cata catador

Cata a tua beleza

Cata cata a natureza

Cata o mistério da flor

Cata cata catador

Cata o pranto

Cata o (en)canto

Cata a lição do amor

Dinorá de Castro Gomes

Outono de 2016

\section{Introdução}

Trazer a alfabetização de adultos catadores para uma experiência transversalizada pela educação ambiental é colocar-se na "Terceira Margem do Rio"1. A inclusão da

1 ROSA, Guimarães. Primeiras Estórias. Editora Nova Fronteira - Rio de Janeiro, 1988, pág. 32. Disponível em: <http://www.releituras. com/guimarosa_margem.asp $>$. Acesso em: 18 fev. 2016, às 18h40min.
Educação Ambiental no trabalho com a alfabetização de adultos catadores direciona o olhar para a imersão em um espaço humano multidimensional e multirreferencial. Um lugar onde "o ser humano é ao mesmo tempo: biológico, psíquico, social, afetivo e racional" (MORIN, 2003, p. 38). Esse trabalho com os adultos catadores requer, portanto, entender o conhecimento envolvendo as mais diversas áreas, sob a perspectiva da totalidade complexa.

A abrangência da experiência realizada adentra situações localizadas no tempo e no espaço que acompanham a realidade dos catadores colaboradores da pesquisa realizada e interagir com esse contexto foi o grande desafio para a efetivação daquela experiência com os catadores. Para enfrentar esse desafio, entendemos que era necessário, dentre tantas escutas, apreender a ordem que regia as relações da teia de sustentação da vida na comunidade onde a experiência se efetivava, buscando maior aproximação entre aquela realidade e a experiência de alfabetização que se pretendia realizar.

A conscientização não está baseada sobre a consciência, de um lado, e o 
mundo, de outro; por outra parte, não pretende uma separação. Ao contrário, está baseada na relação consciência mundo.

Tomando esta relação como objeto de sua reflexão crítica, os homens esclarecerão as dimensões obscuras que resultam de sua aproximação com 0 mundo. A criação da nova realidade [...], não pode esgotar o processo da conscientização. A nova realidade deve tomar-se como objeto de uma nova reflexão crítica (FREIRE, 1979, p. 15).

O campo da educação ambiental popular emerge, então, com a força da realidade que o origina e com o desafio de dimensões imensuráveis ao se posicionar na contramão da exploração, da fome, da injustiça, de tudo aquilo, enfim, que atenta contra toda manifestação da vida no planeta. Bases sobre as quais se sustenta a lógica de mercado capitalista assentada na compra e venda de produtos retirados da natureza e consumidos desenfreadamente, na obsessão do lucro, enquanto consome o próprio ser condicionando a sua inserção ou exclusão social ao seu poder de pertencimento a esse ciclo consumista.

A interação com essa realidade, na experiência vivida junto com os catadores, cuja maior fonte de sustento provinha das relações com uma cooperativa de resíduos sólidos, nos impelia a romper com padrões mutiladores, sob os quais a nossa sociedade é predominantemente concebida. $\mathrm{O}$ lugar existencial por meio do qual avistávamos aquela realidade, nos colocava em busca de um olhar integrador, um olhar capaz de superar as fragmentações e que nos permitisse perceber a totalidade integradora dos elementos que constituíam o corpo "matrístico" (MATURANA, 2004) de sustentação da vida naquela comunidade.

Assim, fomos nos dando conta de que a nossa existência habita uma zona de não resistência localizada em dimensões fora da percepção de nossa capacidade humana racional, que nos lançam na terceira margem do rio. Se a busca que estamos empreendendo atualmente no universo da EA é pela percepção de outra lógica de compreensão e, especialmente, de interação com o mundo, então, os mesmos pares binários fragmentados pela lógica cartesiana: parte-todo, simples-complexo, local-global, unidade-diversidade, particular-universal, são retomados a partir do princípio hologramático proposto por Morin (2015) que afirma que a parte não somente está dentro do todo, como o próprio todo também está dentro das partes, ressurgindo como capazes de nos conduzir a uma nova escuta, uma escuta agregadora concebida na inteligência do coração.

O percurso que trilhamos segue sustentado por essas águas que nos localizam na "Terceira margem do rio", pois na medida em que identificamos o objeto de pesquisa e tentamos responder às questões que a conduzem vamos encontrando lu- 
gar para os questionamentos existenciais. Afinal, como saber qual a contribuição da EA para uma aprendizagem significativa, sem vivenciar essa experiência em meus próprios caminhos internos? Como propor uma educação transformadora e significativa sem iniciar essa transformação em mim e, por conseguinte, nas estratégias ecopedagógicas de minhas práticas docentes? A terceira margem, portanto, é o local onde a escuta sensível pode ser feita, local onde os ruídos ecoam ao percorrer os caminhos de dentro. É o local das origens, sonhos e realizações, da busca de sentidos integradores da existência, de conexões entre os caminhos, de pertencimento.

A terceira margem é a própria lógica do terceiro incluído manifestada pela prática da transdisciplinaridade, ao que NICOLESCU (2000, p. 142-143) explica que

Ao fluxo de informação que atravessa de maneira coerente os diferentes níveis de realidade corresponde um fluxo de consciência atravessando coerentemente os diferentes niveis de percepção. Os dois fluxos são inter-relacionados porque eles compartilham a mesma zona de não resistência. Conhecimento não é nem exterior nem interior: ele é simultaneamente exterior e interior. Os estudos do Universo e do ser humano sustentam um ao outro. A zona de não resistência desempenha o papel do terceiro secretamente incluído que permite a unificação do Sujeito transdisciplinar e do Objeto transdisciplinar, sem que haja a supressão de suas diferenças. (Grifos do autor)

O momento de encontro do grupo dos catadores na sala de aula geralmente era alegre e festivo. Havia muita conversa e muitos risos, o encontro estimulava as manifestações espontâneas e descontraídas. A transdisciplinaridade brotava naturalmente por meio dessas manifestações, elas faziam parte de uma contextualização que atualizava o conhecimento do conhecimento existente naquela realidade, tematizando e resultando no envolvimento de atividades de leitura e escrita. A experiência de vida, o conhecimento que cada um trazia era o que alimentava as trocas, a inclusão, o pertencimento.

BARBIER (2007) amplia o nosso entendimento, dando-nos segurança na escolha pela pesquisa-ação existencial ao longo de suas explanações, mas especialmente quando explica que:

Desse ponto de vista, as pesquisas-ações que eu empreendo tratam, há anos, de temas muito enraizados na afetividade humana (nascimento, amor e paixão, velhice, morte, sofrimento, autoformação, vida social alternativa, interculturalidade, etc.). Faz parte da natureza da pesquisa-ação assim como da natureza das artes marciais que a obsessão do rigor e da competição desapareça, ao longo da experiência, em prol de sua finalidade repleta de uma complexidade crescente do Potencial Humano. (BARBIER, 2007, p. 67) 
A pesquisa-ação existencial contempla as solicitações do contexto da pesquisa nos fazendo perceber, por conseguinte, que, para este estudo, é necessária uma compreensão capaz de demonstrar a relação existente entre os elementos fundantes da pesquisa: a Educação Ambiental, a Educação Popular, as cooperativas de resíduos sólidos e os sujeitos envolvidos nessa tessitura.

\section{O pertencimento e a cooperação}

A cooperação é água que jorra intensa da fonte da Educação Ambiental. Ao nos inserirmos com uma pesquisa-ação em uma comunidade de catadores, residente no entorno de uma cooperativa de resíduos sólidos, acolhemos a cooperação como tema que despertava aprendizagens e saberes provenientes das relações de vida engendradas por aqueles catadores. A natureza integradora da EA, tendo a cooperação como trilha para sua compreensão do mundo, percebe sua presença nas relações de sustentação da vida e na fonte mesmo da própria vida. Inúmeros estudos têm demonstrado que, em seus diferentes níveis e formas de manifestação, os seres necessitam ajudar-se mutuamente para a garantia de sua sobrevivência. A competição gera sentimentos e pensamentos que se opõem à manutenção da vida, que levam à morte. A cooperação, ao contrário do que as relações sociais predominantes estabelecem, assegura particularidades onde todos participam da elaboração da vida. Em seus estudos, observando a natureza para compreender a sociedade humana, KROPOTKIN (2009, p. 22) apresenta que

A sociabilidade e a luta de todos são, no mesmo grau, uma lei da Natureza. É claro que seria dificílimo estimar, mesmo que superficialmente, a importância numérica relativa de ambas as séries de fatos. Mas, se nos valermos de uma prova indireta e perguntarmos à Natureza "Quem são os mais aptos: aqueles que vivem em guerra ou aqueles que se apoiam mutuamente?", vemos de imediato e sem sombra de dúvida que são estes últimos. Os que adquirem hábitos de ajuda mútua têm mais chances de sobreviver e atingem, em suas classes respectivas, o desenvolvimento mais elevado do intelecto e da organização corporal. Considerando os incontáveis fatos que podem ser apresentados para corroborar essa visão, podemos dizer com segurança que tanto a ajuda mútua quanto a luta de todos contra todos são uma lei da vida animal; mas enquanto fator de evolução, a primeira tem provavelmente uma importância muito maior, na medida em que favorece o desenvolvimento dos hábitos e características que asseguram a manutenção e a evolução da espécie, além de maior bem-estar e melhor qualidade de vida para o indivíduo com o menor dispêndio de energia. 
As ideias de KROPOTKIN (2009) evidenciam que essas forças estão presentes em nossa sociedade, ou seja, "tanto a ajuda mútua quanto a luta de todos contra todos". É entre essas forças que nos movimentamos, mas já é momento da humanidade alertar-se de que, neste atual estágio de vida planetária, ela tem a capacidade de fazer escolhas e definir sobre que tipo de sociedade deseja ter, decidindo sobre o seu próprio destino e o da vida no planeta. O modelo capitalista, determinante das relações sociais, profundamente enraizado entre os humanos, se alimenta da competição e a competição se nutre na seleção onde o vencedor é sempre aquele a quem é dada a melhor condição de competir, é aquele a quem as homenagens são direcionadas, enquanto o perdedor é retirado de cena e entregue às suas mazelas. SINGER (2002, p. 10) comenta que

O que importa entender é que a desigualdade não é natural e a competição generalizada tampouco o é. Elas resultam da forma como se organizam as atividades econômicas e que se denomina modo de produção. O capitalismo é um modo de produção cujos princípios são o direito de propriedade individual aplicado ao capital e o direito à liberdade individual. A aplicação destes princípios divide a sociedade em duas classes básicas: a classe proprietária ou possuidora do capital e a classe que (por não dispor de capital) ganha a vida mediante a venda de sua força de trabalho à outra classe. O resultado natural é a competição e a desigualdade.
Segundo LIMA (2013, p. 31): “As origens históricas nos mostram que a economia solidária resgata as lutas dos trabalhadores no início do século XIX, sob a forma de cooperativismo, que servia como manifestação contra o avanço avassalador do capitalismo industrial." O Cooperativismo surgiu, então, como uma forma de organização social que contribuísse para o fortalecimento dos trabalhadores e a melhoria das condições de vida, se orientando pelos princípios da organização autogestionada, ou seja, um tipo de organização em que não há patrão, todos participam coletivamente das decisões em igualdade de condições.

O pertencimento foi um tema recorrente na pesquisa realizada e se despontou como chave para o entendimento da cooperação naquele lugar. Nas relações humanas, o sentido da ação se faz no pertencimento. A cooperação se distingue de uma ação puramente altruísta, não se trata de uma simples dedicação ao outro, mas, principalmente, uma troca onde todos se beneficiam com a ação. A cooperação é uma forma de relação resultante da evolução do ser, que se percebe capaz de fazer junto, compreendendo que com o outro ele pode realizar mais que sozinho, com o outro ele pode realizar o que não é possível realizar sozinho. A cooperação gera sentimentos verdadeiros de partilha, bem estar, satisfação, gratidão, amorosidade, alegria. Sentimentos partilhados pela evolução do ser. Dessa maneira, a 
cooperação, a ética e a sustentabilidade são elementos acoplados em interação permanente fecundando as águas por onde a EA navega. Este entendimento vai ao encontro do que RIBEIRO (2014, p. 59) comenta sobre cooperação.

A cooperação entre as pessoas acontece quando existe empatia e abertura. Cooperamos com aquilo que acreditamos ser importante para nossas vidas ou para a sociedade. Para que haja cooperação é preciso que as pessoas se sintam parte do processo coletivo ou que se identifiquem com a causa comum. No campo institucional o mesmo princípio se aplica, pois uma instituição se interessa em cooperar em uma iniciativa onde os posicionamentos institucionais sejam respeitados e tenham espaço para se expressar.

A cooperação pode ser compreendida como uma forma de organização social humana, mas, também, com uma abrangência ampliada, aberta à percepção da cooperação como uma organização presente em todas as manifestações da vida na natureza. Assim, perpassando por este entendimento ampliado de cooperação, o cooperativismo aparece como uma forma de organização social humana, uma proposta de mudança num mundo orientado pela lógica de mercado, pelo lucro, pelo grande capital. A incursão pela história do cooperativismo vai demonstrar a relevância desse tipo de organização como alternativa para a reorganização da sociedade, sob os princípios da cooperação e da solidariedade, em lugar dos princípios da competição, rivalidade, disputa. As cooperativas de catadores de resíduos sólidos são um espaço de trabalho e de expressão dos sujeitos que as fazem. Cada cooperativa possui uma história, cada história é parte de uma teia tecida nas sombras da sociedade. A aproximação com a pesquisa registrou um pouco do que se passa no mundo interno de uma dessas cooperativas. As reivindicações, as lutas e os desafios, envoltos em sonhos e emoções, em aprendizagens e ensinamentos. A sustentabilidade e a manutenção da vida no planeta submersas nas relações humanas que se estabelecem no interior de cada uma.

\section{O despertar do catador}

O lixo, a coleta seletiva, o catador. Frágil ciclo de equilíbrio da artificialidade urbana. O lixo é o gerador da coleta seletiva e para falar da coleta seletiva é preciso entendê-lo, pois a coleta seletiva é uma decorrência da produção de lixo. O lixo é um fenômeno puramente humano, na natureza não existe lixo, na natureza tudo tem vida e tudo se renova, lembrando Lavoisier. Em sua caminhada "evolutiva" o homem priorizou sua capacidade inventiva em busca de atender as necessidades de sobrevivência e, assim, foi destruindo a natureza, na medida em que ia inventando formas de se proteger e se alimentar. Mas 
a capacidade inventiva da humanidade não satisfeita somente em proteger-se e alimentar-se, viu que podia acumular, percebeu que acumulando podia fazer trocas e logo notou que podia vender e lucrar.

O comércio, que se alimenta pelo grande estímulo ao consumo, ao mesmo tempo em que depreda desenfreadamente a natureza, provoca um grande acúmulo de lixo produzido pela sociedade humana. Para acomodar esse lixo, a sociedade urbana o despeja em lixões a céu aberto, mas a demasiada produção exigiu uma solução. Então, surgem os aterros sanitários, que passam a conviver com os lixões, e a coleta seletiva. Os problemas gerados obrigam a humanidade a olhar para o lixo que produz e percebe que nem tudo é lixo, se dá conta de que grande parte daqueles rejeitos pode tornar-se matéria prima para a produção de outros objetos. Impelida, então, mais pelo comércio que por uma consciência ambiental, passa a existir a coleta seletiva. Lentamente, esse movimento está conduzindo a humanidade a se dar conta da presença da natureza no lixo produzido, mesmo que ainda distante de uma relação de equilíbrio. Mesmo assim, o homem segue padecendo com as consequências de seus atos enquanto não tomar consciência e respeitar os ciclos de renovação da natureza. Enquanto não se perceber como um ser, assim como tantos outros, fazendo parte da grande teia da vida, sustentada pela água, o fogo, a terra e o ar, amálgama da vida no planeta.
O desrespeito aos ciclos é a destruição da vida, inclusive a vida humana.

A lógica de produção e consumo inventada pelo homem é geradora de produtos que, embora tenham sua origem na natureza, a manipulação humana dificulta o seu retorno ao ciclo natural. Nessa artificialidade, a indústria e o comércio tentam inventar seu próprio ciclo, que se confronta com o grande ciclo natural da vida. $O$ maior desafio, então, passa a ser, encontrar um equilíbrio nesse amplo circuito que envolve a vida. A coleta seletiva, portanto, é um artifício que nasce da necessidade de cuidar do mais pernicioso produto do mundo artificial criado pela humanidade, o lixo. Ela se torna, então, uma conciliação de forças entre o mundo artificial e os ciclos da natureza, conectando-se paradoxalmente aos catadores pelas vias das desigualdades sociais. O catador é um trabalhador urbano que teve sua origem fazendo a coleta dos resíduos sólidos pelas ruas das cidades. Com o surgimento das cooperativas de resíduos sólidos, provenientes da Política Nacional de Resíduos Sólidos, Lei 12.305/2010, o catador passa a ser reconhecido como um profissional, tendo como principal atividade o trabalho com a triagem dos resíduos sólidos provenientes da coleta seletiva.

Na cidade de Goiânia, a coleta seletiva se dá em caminhão apropriado para essa finalidade e em cronograma distinto do recolhimento do resíduo orgânico. Os resí- 
duos sólidos arrecadados são distribuídos em cooperativas instaladas nas periferias da cidade, algumas circundadas por comunidades que têm aí o seu principal sustento. Até 2014, existiam 15 cooperativas cadastradas na prefeitura da cidade de Goiânia e, dentre estas, 7 fomentadas pela Incubadora Social da Universidade Federal de Goiás (UFG), ligada à Pró-Reitoria de Extensão e Cultura (PROEC). Essas cooperativas concentram muitas pessoas e vivem em torno do trabalho de triagem e venda do material reciclável${ }^{2}$. A quantidade de catadores em cada uma está sempre variando, porque boa parte dificilmente se mantém por um longo período nessa atividade, mas cada cooperativa trabalha com uma média de 15 a 20 catadores.

A estrutura para receber os resíduos varia em cada cooperativa. Na maioria das vezes a coleta trazida pelos caminhões é depositada nos pátios onde, no chão mesmo ou sobre bancadas e com pouca proteção de equipamentos, é feita a triagem. Predominam condições precárias de higiene e estrutura. $O$ trabalho realizado é basicamente o de triagem e armazenamento dos resíduos em grandes sacos de lona, que eles denominam de "bags", fornecidos

2 Reciclagem, lei $\mathrm{n}^{\circ} 12.305$, de 2 de agosto de 2010, item XV, Capítulo II, é o processo de transformação dos resíduos sólidos que envolve a alteração de suas propriedades físicas, físico-químicas ou biológicas, com vistas à transformação em insumos ou novos produtos, observadas as condições e os padrões estabelecidos pelos órgãos competentes (...). pelas empresas, as mesmas que retornam para negociar e transportar o material separado. Esses "bags" possuem um tamanho padronizado e servem de unidade de medida. O valor do material vendido é determinado pelo mercado, ou seja, a cooperativa vende para quem pagar mais. $\mathrm{O}$ dinheiro arrecadado é dividido entre os catadores envolvidos, sob a administração de uma liderança escolhida pelo grupo, conforme os preceitos das cooperativas autogestionárias.

O Programa Goiânia Coleta Seletiva (PGCS) percebe a necessidade de fazer a capacitação dos catadores para que eles consigam se organizar e administrar suas associações. A UFG, então, é convidada a prestar essa assessoria. Dessa parceria nasce em 2008 a Incubadora Social da Universidade Federal de Goiás, vinculada à Pró-Reitoria de Extensão e Cultura, com a finalidade de fazer a capacitação e o assessoramento aos empreendimentos dos catadores de materiais recicláveis. Essa Incubadora iniciou imediatamente o atendimento a três associações, mas, impelida pela grande demanda, ampliou rapidamente seu atendimento e em 2011 já estava com 10 grupos sendo atendidos. A adesão desses grupos à Incubadora é voluntária, as cooperativas incubadas é que definem quanto à sua adesão, permanência e saída do vínculo com a Incubadora. Por essa razão, em 2014 havia 7 cooperativas incubadas. A Cooperfam, a CooperMas, a Cooper Rama, a Guarani, a Cooprec, a Coocamare e a Acop. 
O Programa Goiânia Coleta Seletiva (PGCS) percebe a necessidade de fazer a capacitação dos catadores para que eles consigam se organizar e administrar suas associações. A UFG, então, é convidada a prestar essa assessoria. Dessa parceria nasce em 2008 a Incubadora Social da Universidade Federal de Goiás, vinculada à Pró-Reitoria de Extensão e Cultura, com a finalidade de fazer a capacitação e o assessoramento aos empreendimentos dos catadores de materiais recicláveis. Essa Incubadora iniciou imediatamente o atendimento a três associações, mas, impelida pela grande demanda, ampliou rapidamente seu atendimento e em 2011 já estava com 10 grupos sendo atendidos. $A$ adesão desses grupos à Incubadora é voluntária, as cooperativas incubadas é que definem quanto à sua adesão, permanência e saída do vínculo com a Incubadora. Por essa razão, em 2014 havia 7 cooperativas incubadas. A Cooperfam, a CooperMas, a Cooper Rama, a Guarani, a Cooprec, a Coocamare e a Acop.

A Lei $n^{\circ} 12.305$ que legisla sobre a Política Nacional de Resíduos Sólidos (PNRS), sancionada em 02 de agosto de 2010, dava prazo de 4 anos para que as cidades se adequassem às normas dessa política. Para isso, todos os municípios do país teriam que substituir os lixões por aterros sanitários, implantar a coleta seletiva e a reciclagem, o reuso, a compostagem e o tratamento do lixo até 2014. Com essa exigência, a Incubadora da UFG precisou ampliar sua área de atendimento para outros municípios além da região metropolitana de Goiânia, com parcerias via Secretaria Nacional de Economia Solidária (SENAES) e com o Ministério Público do Estado de Goiás.

Com relação a esse prazo estabelecido pela PNRS, muitos municípios alegaram não terem condições de atender as exigências no prazo estabelecido. Em decorrência, no dia 01/07/2015, o Senado aprovou um projeto que prorrogou o prazo para as cidades brasileiras se adequarem às regras da PNRS. De acordo com esse projeto aprovado, os municípios têm o prazo de 2018 a 2021 para se adequarem à PNRS, com critérios que variam de acordo com a localização geográfica, o número de habitantes e a renda. Quanto maior o município e a renda, assim como os de fronteira, menor o prazo. Sobre o empenho dos municípios, o Sr. Fernando, coordenador da Incubadora Social da UFG, em entrevista ${ }^{3}$ para esta pesquisa, comenta:

(1) Eu acho que está como quase todos os lugares que eu conheço, muito fraco, muito tímido, mas isso a gente tem detectado aqui, no decorrer do tempo, que existe o que a gente chama de "a cultura do lixo", nós vivemos sob a cultura do lixo e nós temos percebido que tanto a sociedade e os governantes percebem os materiais que são descartados, não importa se é reciclável 
ou não, isso é lixo. (...) Então, a gente vê governantes de municípios que não se preocupam em fazer essa distinção entre o que é material reciclável ou não, para que as pessoas possam compreender que o material reciclável não é lixo, é material limpo, é material gerador de trabalho e renda. Essa eu creio que é a maior das dificuldades por estarmos submetidos à cultura do lixo. Então, investir nesse segmento não é uma coisa que está dentro dos planos, desde que tirou da frente da casa, sumiu, já resolveu o problema.

(2) Então nós percebemos que é muito comum, a gente observa, isso é visivel, por exemplo, o investimento em propaganda dos governos muito maior do que em uma estrutura dessa natureza. Então, no meu entender, que eu vejo essa relação entre Educação Ambiental e Coleta Seletiva, [...] acho que o ponto de partida é a educação ambiental, mas ela de certa forma orientada para quebrar esse paradigma que vem amarrado nesse aí chamado de cultura do lixo, esse é o grande problema que nós vivemos aí.

Esse comentário do Sr. Fernando esclarece que a prorrogação do prazo dado aos municípios para o cumprimento da Lei de PNRS, não resolve a situação, porque se o prefeito não tiver consciência ambiental ele nunca vai conseguir cumprir o que está estabelecido nessa diretriz, ou em qualquer outra, não importa qual seja o prazo. O problema não está na Lei ou nos prazos, o problema está na falta de Educação Ambiental, no analfabetismo ambiental dos governantes. A PNRS não se integra à visão estreita de muitos governantes submergidos em suas astuciosas políticas eleitoreiras. Essa tem sido uma grande dificuldade encontrada no trabalho da Incubadora e é também uma grande barreira para o avanço do trabalho ambiental. $\mathrm{A}$ Incubadora está no meio de uma cadeia, tentando fazer o elo entre as partes que a mantêm.

Cada cooperativa visitada possui uma história e em cada história uma gota a mais que se desprende das narrativas ocultadas nas sombras das águas de nossa sociedade. As cooperativas visitadas trazem de comum entre elas um grupo de pessoas que experimentam o espaço mais dolorido da nossa sociedade, pessoas que sabem o que é a fome pra além do intervalo entre uma refeição e outra. Pessoas espectadoras do mundo consumista e que se consomem na lida com os resíduos sólidos, mas pessoas cujas águas permanecem aquecidas pelo calor de suas emoções, na partilha da vida, no cultivo coletivo dos sonhos. Dentre estas, destaco a cooperativa Cooprec e a Acop, por serem pioneiras nesta experiência em Goiânia e guardarem memórias de uma relevante história da experiência da EA vivida nesta cidade.

A cooperativa Acop e a Cooprec são as grandes pioneiras na experiência da coleta seletiva em Goiânia. Elas viveram essa experiência de maneira diferente, a partir do contexto de cada uma. A Cooprec era composta por pessoas que moravam nos 
bairros do seu entorno, cada uma tendo o seu lugar de moradia nesses bairros, ou nas proximidades e trabalhavam nos serviços da cidade: domésticas, babás, serviços gerais, ajudantes de pedreiro e até catadores, dentre outros. A Acop era composta por pessoas que não tinham onde morar, elas moravam em uma favela debaixo de uma ponte, sobre os trilhos de trem de uma linha desativada. Pessoas que viviam da coleta de material reciclável, andando pelas ruas, puxando os seus carrinhos, como meio de sobrevivência. A cooperativa foi uma maneira de se organizarem para lutarem também por moradia. A diferença fundamental entre essas duas histórias é que uma cooperativa foi entregue pronta, equipada, estimulando um grupo a tornar-se catador, enquanto a outra foi fruto da luta de quem era catador, mesmo sem ter uma cooperativa.

Em entrevista para esta pesquisa Naná ${ }^{4}$ fala sobre as lutas com propriedade:

(1) Olha, acho que toda cooperativa, desde o começo, tem uma luta, uma caminhada. Então se ela não lutar, se ela não caminhar, nada vai pra frente. Se ela não correr atrás, não vem, as coisas não caem do céu. Primeiro, através da luta ela tem um sonho, que é o sonho de ser estruturada, de ser bem sucedida, com galpões, eles fica sonhando. Cooperado que é cooperado sonha. "Vamo ter uma prensa, vamo

Entrevista $\mathrm{n}^{\circ}$ 02, de 09/03/2015. fechar isso aqui, vamo ter isso, vamo ter uma sala de jogos, um refeitório", eles fica sonhando. Eu falo por mim que eu sonhava mais a Maria $W$ - que a gente via essas empresa grande, eu falava: "já imaginou?". A gente fica com aquele sonho. $E$ através dos sonhos a gente gera as movimentações, as lutas, as conquistas, as reuniões... As vezes a gente faz manifestações também, através de tudo um vai puxando o outro.

Naná é uma catadora filha de catadores, ela e os irmãos cresceram ajudando seus pais na coleta, por isso, conhece profundamente a vida de catador e fala com propriedade sobre as lutas e os sonhos do catador, ao mesmo tempo em que demonstra já ter se dado conta de como tudo está conectado: a cooperativa, o cooperado, os sonhos, as movimentações, as caminhadas, as reuniões, as lutas, as conquistas, as manifestações, "um vai puxando o outro".

Ao longo da pesquisa, percebemos o distanciamento do catador ao processo de escolarização. Seu Iramar, presidente da Acop no ano 2014, catador atuante, representante do movimento nacional dos catadores no Estado de Goiás e um dos membros da Comissão Nacional do Movimento Nacional dos Catadores de Material Reciclável (MNCR), sabe do valor da escolarização para o fortalecimento das lutas e, consequentemente, para a melhoria das condições de trabalho e vida. Em entrevista concedida para esta pesquisa no 
dia16/04/2015, ele comenta sobre a importância do catador saber ler e escrever.

(1) Pra todo cidadão, assim, que tem conhecimento da verdade de leitura, pra gente é fundamental sê saber ler e escrever. No processo de cooperativa, a gente vai trabalhar também com vários tipos de equipamento, e você tem que ter o conhecimento como é o manual desses equipamento, como é que você vai fazer uma leitura do manual de equipamento que você vai usar se você não sabe ler?

(2) No caso, hoje eu estou como presidente, sei ler, sei escrever e tal. Amanhã ou depois, qualquer outro cooperado que tá aqui dentro pode ser um presidente, e como é que ele vai ser presidente se ele não sabe assinar os documentos que precisa ser assinado? Assinar uma folha de cheque pra fazer o pagamento dos cooperados, tudo isso... Pra fazer a assinatura num projeto de uma parceria, de um convênio com a Prefeitura, com o Ministério Público, tudo isso a gente tem que saber ler. Você lê o instrumento lá, que antes de assinar você lê, tem o conhecimento. Hoje, na verdade você tá tratando com pessoas do poder público e tudo, mas nem tudo a gente deve expressar uma confiança total naquilo que tá escrito no papel. Estar ciente realmente, ler um pouco antes de assinar, ter o conhecimento realmente. Ah, não, eu tô ciente do que que tá acontecendo, então eu posso assinar sabendo o que eu tô assinando.

(3) Se os companheiro não tiver um incentivo pra buscar se alfabetizar, pra se formar, pra se capacitar... Hoje a gente já tem até satisfação de falar. Tem uma catadora lá em Anápolis que ela trabaIhava no lixão e estudava. Aí ela saiu do lixão, tá na cooperativa, continua a estudar, se formou agora no começo desse ano. Não me recordo bem a matéria, agora já tá fazendo a faculdade.

A escolarização dos catadores é da maior importância para que possam se afirmar como profissão, defendendo seus interesses e participando como atores ativos no processo. O socioambientalismo tem a emancipação como objetivo a ser alcançado por meio da EA crítica e essa emancipação ocorre quando os sujeitos se tornam agentes do processo, elaborando, pensando, definindo e se organizando com autonomia, sem depender de agentes públicos ou instituições para isso.

Observamos que a vida das cooperativas se mantinha em meio a épocas boas e outras de crise, uma irregularidade que se manifestava na remuneração dos catadores, eles mesmos nunca sabiam ao certo quanto receberiam em cada mês. $F$ Catador explica essa realidade e, ao mesmo tempo, tece uma crítica e apresenta a sua sugestão:

(1) O ser humano, a classe média, ele não dá valor aos cooperados, porque se ele desse valor, as cooperativa era botado lá em riba. Como que nós tamo ajuntando, nós tamo ajuntando aquele material que aquelas pessoas joga fora, que tá gerando emprego e renda para a gente, ele se torna o pão de cada dia 
nosso. E o governo federal ou estadual, se quisesse ajudar, abrisse os olhos, ele podia pagar um salário para cada cooperado, fora os material que ele pega.

A situação vivida por esses catadores é um desdobramento da falta de conexão entre a atividade que desenvolvem, o material que chega na cooperativa e a participação da sociedade na coleta seletiva. Falta de ações do poder público no cuidado com o lixo e com a coleta seletiva, uma realidade complexa e que pede urgência em seu tratamento. Aos catadores resta uma condição degradante, em decorrência da falta de envolvimento da sociedade com ações educativas de preservação do meio ambiente. A todos nós resta aprendermos que a nossa existência somente se mantém, em conexão com ações solidárias, em conexão com a rede de sustentabilidade da vida no Planeta Terra.

\section{Considerações}

A Educação Ambiental como estratégia de alfabetização de adultos catadores foi a maneira empregada para analisar a contribuição da Educação Ambiental para alfabetização e formação humana junto a uma turma de trabalhadores de uma cooperativa de resíduos sólidos na cidade de Goiânia. Para localizar esses sujeitos percorremos 8 cooperativas de catadores vinculadas à Incubadora Social da UFG, em 2013 e 2014, aplicando um questionário para buscar os dados pessoais e escolares desses catadores. Dessa maneira, a comunidade onde a experiência se desenvolveu pôde ser revelada. Assim, a experiência foi desenvolvida, no ano de 2014, em uma comunidade de catadores que vivia no entorno de uma cooperativa de resíduos sólidos, a cooperativa Acop, situada no Setor Albino Boaventura, na Região Noroeste da cidade de Goiânia. Ela revelou, entre os sujeitos envolvidos, a resistência, a baixa autoestima e o distanciamento à vida escolar. Ao mesmo tempo, desvendou o desejo contido, a satisfação de estudar, a alegria por estarem em uma escola deles, inserida naquela comunidade e na realidade de suas vidas. $O$ resgate do ser, do pertencimento e o reconhecimento do valor do catador como um profissional digno e importante para a sociedade urbana atual, foram um caminho para despertar o desejo de aprender a ler e a escrever. Dessa maneira, a alfabetização de adultos trouxe a Educação Popular como campo de diálogo com a EA proporcionando o encontro de elos submersos capazes de originar uma experiência enriquecedora no processo de alfabetização.

A falta de orientação e estímulo à população para que participe da coleta seletiva é uma grande barreira que ainda precisa ser transposta. A coleta seletiva é um fio condutor que nos entrelaça, que nos conecta com a construção de uma cidade sustentável, um tipo de cidade que somente 
pode ser construída com a participação de todos. Amplas campanhas publicitárias na televisão, nos jornais, nas escolas e universidades, em praças e painéis precisam ser feitas orientando e estimulando a coleta, assim como apresentando e valorizando o catador, envolvendo toda a população na importância da colaboração de todos num grande movimento solidário em defesa da vida, onde todos se beneficiam ao participar desse grande ciclo solidário. Ações que nos parecem simples, mas capazes de causar uma grande movimentação em toda a cidade, envolvendo-a em um ambiente de profunda e imensurável transformação. Esse deve ser o desafio posto àqueles que se comprometem com essa realidade na construção de um mundo meIhor, mais justo e mais humano.

A precariedade da vida dos catadores submersos no submundo da exclusão, associada à falta de escolarização, submete esses catadores à sujeição de uma condição social que Ihes rouba também a competência de se perceberem como sujeitos capazes de transformar essa condição. Dessa maneira, entendemos que é necessário dar as mãos e estimular a organização do movimento dos catadores, ampliando ações em defesa desses sujeitos e das cooperativas a partir da diversidade de possibilidades apontadas pelo contexto da realidade de cada uma delas. Nesse sentido, considero que a Incubadora Social, como órgão de extensão de uma Universidade Federal, a UFG, aberta à multirre- ferencialidade do conhecimento, pode ter um papel relevante à frente da diversidade de ações que podem ser implementadas em um movimento intensificado e contínuo de fortalecimento das cooperativas. Um movimento que não se efetiva apenas no suporte logístico, mas em uma formação que Ihes amplie a visão das possibilidades de transformação, que Ihes faça perceberem a força de mudança que eles conduzem, um movimento de superação da naturalização da submissão.

Os conflitos, as tensões, a fome, o aquecimento global, as doenças, o descontrole da vida, está levando a humanidade a se dar conta cada dia mais de que há algo de errado com a escolha de desenvolvimento que tomou. Ela já percebeu que não pode haver desenvolvimento em desarmonia com a natureza e que esta está chegando ao seu limite de sustentação da vida, em decorrência da exploração desenfreada e desrespeitosa de seus ciclos. Agora, o dilema é um só: ou a humanidade abre mão do seu modelo de desenvolvimento econômico sustentado na destruição da natureza, ou abre mão da vida no Planeta Terra, dentre essas, a própria vida humana. Embora esteja consciente desse dilema, a humanidade ainda não conseguiu fazer outras escolhas e mudar o rumo de sua trajetória no Planeta.

É esse o contexto onde se localizam as cooperativas de catadores de Goiânia, elas fazem parte desse ciclo de manutenção da 
vida que envolve toda a sociedade. O modelo autogestionário é mais um ponto de coerência entre o funcionamento dessas cooperativas e o princípio de solidariedade e respeito à vida capazes de mudar essa trajetória do Planeta. A manutenção, portanto, de condições adequadas de funcionamento dessas cooperativas está vinculada à própria tomada de decisão da humanidade quanto ao seu modelo de desenvolvimento. A coleta seletiva e as cooperativas podem, portanto, se fortalecer e originar um movimento capaz de impelir a humanidade a fazer a opção pela vida.

\section{Referências bibliográficas}

BARBIER, René (2007): A Pesquisa-Ação. Brasília, Liber Livro Editora.

FREIRE, Paulo (1979): Conscientização: teoria e prática da libertação: uma introdução ao pensamento de Paulo Freire / Paulo Freire. Tradução de Kátia de Mello e Silva; revisão técnica de Benedito Eliseu Leite Cintra. São Paulo, Cortez \& Moraes.
KROPOTKIN, Piotr (2009): Ajuda Mútua: um fator de evolução. Tradução Waldyr Azevedo Jr. São Sebastião, A Senhora Editora.

MATURANA, Humberto R. e VERDEN-ZÖLLER, Gerda (2004): Amar e Brincar: fundamentos esquecidos do humano. Tradução de Humberto Mariotji e Lia Diskin. São Paulo, Palas Athenas.

MORIN, Edgar (2003): Os sete saberes necessários à educação do futuro. 8 ed.-São Paulo, Cortez; Brasília, DF, UNESCO.

MORIN, Edgar (2015) Introdução ao pensamento complexo. 5 ed. Porto Alegre, Sulina.

NICOLESCU, Basarab (2000): Um novo tipo de conhecimento-transdisciplinaridade e A prática da transdisciplinaridade. In: Educação e Transdisciplinaridade. Brasília, UNESCO.

RIBEIRO, Sérgio (2014): A transdisciplinaridade como caminho para a cooperação para a água. In: RIBEIRO, Sérgio; CATALÃO, Vera; FONTELES, Bené. Água e cooperação: reflexões, experiências e alianças em favor da vida. Brasília, Ararazul, Organização para a Paz Mundial.

SINGER, Paul (2013): Prefácio. In: LIMA, Ma Isabel R. Economia Solidária e Vínculos. São Paulo, Ideias e Letras.

SINGER, Paul (2002): Introdução à economia solidária. $1^{\mathrm{a}}$ ed. São Paulo, Editora Fundação Perseu Abramo. 